\title{
Management of colorectal cancer follow-up in elderly patients
}

\author{
S Puleo*, T R Portale, A Pesce, M A Trovato, G Li Destri \\ From de Senectute: Age and Health Forum \\ Catanzaro, Italy. 5-7 December 2009
}

\section{Background}

Follow-up of surgically treated colorectal cancer patients is not supported by objectively certain data. Despite the thousands of investigations reported in the literature, only six randomized prospective studies and two meta-analysis of randomized studies provide data suggesting clear conclusions until today. The main goal of colorectal follow-up is to improve patient survival by early diagnosis of recurrence during the asymptomatic stage when radical surgical treatment is more viable [1]. However the reduction of global mortality from colorectal cancer achieved by follow-up, radical second-surgery and therefore new and definite patient recovery calculated in our patients in follow-up on 5 years disease free interval was only $2.6 \%$ according to the findings of other authors [2,3]. In our recent study carried out on a group of 280 patients in our follow-up the average age was 69.5 demonstrating that the age must be carefully considered in order to establish the follow-up timing and modality and to calculate the cost-benefit ratio. In our experience the far from brilliant results obtained led us to change our follow-up in 2006 and make it less intensive, tailoring it to the stage of the disease, the reliability of the diagnostic methods, times of recurrences and no less important, the age of patients. In the aged obviously the surgical and/or adjuvant and neoadjuvant treatments are to be considered with caution and local and general controindications to every type of therapy carefully evaluated. The age is a fundamental part of ASA, POSSUM and PST and could condition the therapeutical strategies. On the other hand many reports confirm the possibility of performing safe operation for liver and lung metastases or local recurrences in the elderly without a statistical higher rate of morbidity and mortality compounding with younger adults. Lastly, in our policy we have considered the agreement of elderly patients to modality and timing of follow-up on the

basis of a study carried out with the collaboration of a psychological team. On the basis of those experiences we also believe that in some patients and circumstances a major involvement of family doctors substituting the institutional follow-up staff is necessary.

\section{Conclusions}

Thus, even if the follow-up is lacking in evidence of benefits it remains a "good practise": however in the elderly we have to reflect, as does Smith in 1998, "is it really better to know one has incurable metastases earlier than to believe one is well when one feels well?"

\section{Published: 19 May 2010}

\section{References}

1. Anthony T, Fleming JB, Bieligk SC, Sarosi GA, Kim LT, Gregorcyk SG, et al: Postoperative colorectal cancer surveillance. Journal of the American College of Surgeons 2000, 190(6):737-49.

2. Meyerhardt JA, Mayer RJ: Follow-up strategies after curative resection of colorectal cancer. Seminars in Oncology 2003, 30(3):349-60.

3. Kievit J: Follow-up of patients with colorectal cancer; numbers needed to test and treat. European Journal of Cancer 2002, 38(7):986-99.

doi:10.1186/1471-2318-10-S1-A27

Cite this article as: Puleo et al:: Management of colorectal cancer

follow-up in elderly patients. BMC Geriatrics 2010 10(Suppl 1):A27.

Submit your next manuscript to BioMed Central and take full advantage of:

- Convenient online submission

- Thorough peer review

- No space constraints or color figure charges

- Immediate publication on acceptance

- Inclusion in PubMed, CAS, Scopus and Google Scholar

- Research which is freely available for redistribution 